\title{
RUSSELL'S PARADOX: A HISTORICAL STUDY ABOUT THE PARADOX IN FREGE'S THEORIES
}

\author{
Aline Germano Fonseca Coury \\ Denise Silva Vilela \\ Universidade Federal de São Carlos - UFSCar - Brasil
}

(aceito para publicação em fevereiro de 2019)

\begin{abstract}
For over twenty years, Frege tried to find the foundations of arithmetic through logic, and by doing this, he attempted to establish the truth and certainty of the knowledge. However, when he believed his work was done, Bertrand Russell sent him a letter pointing out a paradox, known as Russell's paradox. It is often considered that Russell identified the paradox in Frege's theories. However, as shown in this paper, Russell, Frege and also George Cantor contributed significantly to the identification of the paradox. In 1902, Russell encouraged Frege to reconsider a portion of his work based in a paradox built from Cantor's theories. Previously, in 1885, Cantor had warned Frege about taking extensions of concepts in the construction of his system. With these considerations, Frege managed to identify the precise law and definitions that allowed the generation of the paradox in his system. The objective of this paper is to present a historical reconstruction of the paradox in Frege's publications and discuss it considering the correspondences exchanged between him and Russell. We shall take special attention to the role played by each of these mathematicians in the identification of the paradox and its developments. We also will show how Frege anticipated the solutions and new theories that would arise when dealing with logico-mathematical paradoxes, including but not limited to Russell's paradox.
\end{abstract}

Keywords: Mathematics, History, Russell's Paradox, Gottlob Frege. 


\section{[PARADOXO DE RUSSELL: UM ESTUDO HISTÓRICO SOBRE O PARADOXO NAS TEORIAS DE FREGE]}

\section{Resumo}

Por mais de vinte anos, Frege buscou os fundamentos da aritmética através da lógica, de modo a garantir a verdade e a certeza do conhecimento. Entretanto, quando acreditava que sua obra estava quase completa, Bertrand Russell comunicou-o através de uma carta que seu sistema gerava um paradoxo, conhecido atualmente como o paradoxo de Russell. Comumente, considera-se que Russell identificou o paradoxo nas teorias de Frege, principalmente devido à carta. Apesar disso, como será apresentado neste artigo, Russell, Frege e até mesmo George Cantor contribuiram de maneira significativa na identificação do paradoxo. Em 1902, Russell encorajou Frege a reconsiderar uma parte de seu trabalho tendo por base um paradoxo construído a partir das teorias de Cantor. Anteriormente, em 1885, Cantor alertou-o sobre utilizar extensão de conceito de maneira tão significativa na construção de seu sistema. Com essas considerações, Frege identificou a lei e definições exatas que permitiram a geração do paradoxo dentro do seu sistema. O objetivo deste trabalho é apresentar uma reconstrução histórica do paradoxo nas publicações de Frege e discuti-lo considerando as correspondências trocadas entre ele e Russell. Será discutido também o papel que cada um desses matemáticos desempenhou na identificação do paradoxo e nas tentativas de solucioná-lo. Dessa forma, mostraremos como Frege antecipou soluções e novas teorias que surgiriam para lidar com os paradoxos lógico-matemáticos, incluindo, mas não restrito ao paradoxo de Russell.

Palavras-chave: Matemática, História, Paradoxo de Russell, Gottlob Frege.

\section{Introduction}

Many mathematicians have dedicated their lives attempting to find a way to build a mathematical system capable of proving all mathematical truths. Historically, mathematics has been regarded as an exact science, the base of all other exact scientific fields, and therefore, not only the root of truth, but as truth itself (DAVIS; HERSH, 1981). Hence, mathematics should have solid foundations, ensuring that all its theorems and statements could be used unquestionably.

Until the $19^{\text {th }}$ century, mathematicians believed that mathematics foundation was well consolidated based on Euclidean geometry. This belief was shaken by investigations into the parallel axiom ${ }^{1}$. Mathematicians were suspecting that this axiom could be derived

\footnotetext{
${ }^{1}$ Also called the fifth postulate, the parallel axiom can be enunciated as follows: "That, if a straight line falling on two straight lines make the interior angles on the same side less than two right angles, the two straight lines, if
} 
from the others, so they tried to show if it was dependent on them. These investigations led to non-Euclidean geometries ${ }^{2}$, what showed that perhaps Euclidean geometry would not be the most secure base to build a foundation for all mathematics theories.

In this period, mathematicians such as Augustin-Louis Cauchy (1789-1857), Richard Dedekind (1831-1916), Karl Wilhelm Theodor Weierstrass (1815-1897), Georg Cantor (1845-1918), Charles Méray (1831-1911) and Heinrich Eduard Heine (1821-1881) were all working in the foundations of mathematics. Cauchy started to formalize the infinitesimal calculus theory, proving its theorems in a formal way. Dedekind and Weierstrass tried to build a foundation for mathematics based on arithmetic instead of geometry. Cantor, Méray and Hein were working on the arithmetization of analysis project (BACHA; SAITO, 2014), (VILELA, 1996).

Besides these mathematicians, Friedrich Ludwig Gottlob Frege (1848-1925) idealized mathematics as truth and tried tirelessly to find an axiomatic system for the foundations of arithmetic. Frege was concerned about systematizing definitions and proof methods. He sought in logic the tools to build a foundation for arithmetic, trying to show that arithmetic grows out from logic. In such system, any mathematical statement considered to be true could be proved (GUILLEN, 1983).

Frege worked in his logicist project ${ }^{3}$ for over twenty years, culminating in the publication of three books: Begriffsschrift (1879), Die Grundlagen der Arithmetik (1884) and Grundgesetze der Arithmetik ${ }^{4}$ in two volumes (1879/1903). The books, as will be presented later, show the path traced by Frege in the construction of an axiomatic system for arithmetic. In 1902, when Frege had finished writing the second volume of Grundgesetze, he believed that his dream had been fulfilled, i.e., he believed he had built a system sufficient and strong enough to express and prove all arithmetic truths (FREGE, 1903). In the same year, he received a letter from Bertrand Russell (1872 -1970), informing him about a flaw, which Frege notice could be derived from one of his laws. This inconsistency is now known as Russell's paradox.

This paper presents the results of our research whose main goal was to reconstruct Russell's paradox in its original formulation in Grundgesetze der Arithmetik. The research is characterized as historical and bibliographical. As primary sources, we analyzed the

produced indefinitely, meet on that side on which the angles are less than the two right angles" (HEATH, 1956, p. 155).

${ }^{2}$ Mathematicians discovered that different geometries could be constructed where, for example, given a line $r$ and an external point $A$ there is no line passing through $A$ and parallel to $r$ (or others where there are infinite lines passing through it). See Davis and Hersh (1981).

${ }^{3}$ The logicist school of thought is based on Aristotelian classical logic. According to this school of thought, mathematics would be an extension of logic, that is, mathematics would be reducible to logic.

${ }^{4}$ - Begriffsschrift, eine der arithmetischen nachgebildete Formelsprache des reinen Denkens. Halle a. S., L. Nbert, 1879, X, 88p. Cf. [48]. / Ideography, a formula language, modeled upon that of arithmetic, for pure thought.

- Die Grundlagen der Arithmetik. Eine logisch-mathematische Untersuchung über den Begriff der Zahl. Breslau, W. Koebner, 1884, XI, 199p. /The Foundations of Arithmetic: a logico-mathematical enquiry into the concept of number.

- Grundgesetze der Arithmetik, Begriffsschriftlich abgeleilet. I. Band. Jena, H. Pohle, 1893, XXXII, 253p. /The Basic Laws of Arithmetic. Volume I.

Grundgesetze der Arithmetik, Begriffsschriftlich abgeleilet. II. Band. Jena, H. Pohle, 1903, XV, 265p. /The Basic Laws of Arithmetic. Volume II.

RBHM, Vol. 19, n 37, p. 95-116, 2019 
books Begriffsschrift, Die Grundlagen der Arithmetik, Grundgesetze der Arithmetik volumes 1 and 2 by Frege and the correspondence exchanged by Russell and Frege between 1902 and $1912^{5}$. Here, Frege's publications will be referred to in the following way: BS (1879) (Begriffsschrift), GA (1884) (Die Grundlagen der Arithmetik), GG (1893) and GGII (1903) (Grundgesetze der Arithmetik volumes one and two, respectively) ${ }^{6}$. The secondary sources were Russell's Principles of Mathematics (1903) and Principia Mathematica (1910), and books or articles by scholars specialized on Frege's work, such as Sluga (1999), Beaney (2005), da Silva (2007), Van Heijenoort (1970), Furth (1964) and Alcoforado (2009), Grattan-Guinness (1978), Wehmeier (2004), among others.

The discussions in this paper will be presented paying special attention to the contents necessary for understanding the arguments used by Frege and Russell in the correspondence, and hence to understand the role played by each of them in the discussions about the origin and developments of the paradox. Also, we intend to point out Cantor's influence in the whole discussion, either by reviewing Frege's work or by identifying the paradox generated inside his own theories. With these discussions, we intend to show that Frege himself had a determinant role in the whole process by either specifying the laws and definitions that generated the paradox or anticipating the theories that would arise from these discussions. We shall, besides reinforcing Russell's work, known as one of the most important mathematicians and philosophers of all time, show the fundamental role played by Frege in the development of logic and mathematics and how his paradox became the milestone that paved the way for new theories.

Although the $19^{\text {th }}$ century was a period of the identification of many paradoxes (HERSH, 1997), Russell's could be considered the last straw. According to Fraenkel, BarHillel and Levy (1984, p.2), it was the first time that a paradox emerged at "such an elementary level involving so strongly the most fundamental notions of the two most 'exact' sciences, logic and mathematics". Da Silva (2007, p.134, our translation) states that this paradox was "one of the stars of a kind of 'paradox season' that was apparent at this time": they "appeared all over the place and installed the so-called "crisis in the foundations".

The discovery of these paradoxes in mathematical theories was unbeareble for most mathematicians. According to Hilbert, Poincaré and Cantor, "existing has only one meaning in mathematics, to be free from contradictions" (DA SILVA, 2003, p.30, our translation).

The identification of Russell's paradox in Frege's work brought both immediate and long-term consequences. Although some mathematicians abandoned the idea that logic would be the basis of mathematics, others attempted vigorously to fix the notions and definitions in set theory, which led to a great progress in mathematical, philosophical and logical theories. Despite the initial shock, Frege was one of those who tried to find a way to

\footnotetext{
${ }^{5}$ Due the historical characteristic of this research, in some points there may be differences between the pages in the quote/citation presented by us and the one presented in the original work. The difference is related with the publication/translation version used.

6 These works will be here cited by the original date of the publication, independently of the publication/translation used in the research.
} 
remove the paradox from his axiomatic system (ALCOFORADO, 2009). In the end, they were not able to get rid of Russell's paradox (FRAENKEL, et. al. 1984).

The definitive conclusion for the foundation problem appeared in 1931, when the logician Kurt Gödel (GOLDSTEIN, 2008) shocked mathematicians with his incompleteness theorems which was the last nail in the coffin of the dream of creating a foundation for arithmetic using classical logic. Gödel proved that if we can build an axiomatic system strong enough to serve as a foundation of arithmetic, it will not be possible to prove its consistency within the system itself.

Although Gödel's theorems seemed to close the door for the path toward the definitive foundation, this fruitful intellectual moment resulted in the development of many important mathematical, philosophical and logical theories: non-classical logics could show their strength; a formalized axiomatic set theory emerged; and an outstanding student of Russell's, Ludwig Wittegenstein (1889-1951), opened up new possibilities for a new nonessentialist and non-fundamentalist philosophy.

Frege's work, and thus the paradox, was one of the "fertilizers" for the flourishing of all these new theories. Thus, studying Russell's paradox in Frege's work means investigating a rich and fruitful moment in the history of philosophy, mathematics and logic. For mathematics, the paradoxes mean the end of truth and certainty, which has consequences in philosophy of science. For logic, it is a milestone that resulted in the development of non-classical logics and in the attempt to formalize set theory. For philosophy, it is possibly the antecedent of the movement known as linguistic turn.

In the next section, the trail followed by Frege in his attempt to build a foundation for arithmetic will be presented. It will be emphasized Frege's dedication (from 1875 to 1902) to the project of creating a new logical language, but paying special attention to the definitions and law that generate the paradox. Then, the following section will approach the paradox, including an analysis of the correspondence exchanged by Frege and Russell, the derivation of the paradox and the proposals presented by them to solve it. In this same section, it will be showed that Frege himself specified the origin of the paradox inside his theories. The final section will present how Frege's proposed pathways to solve the paradox also show traces of respected theories that arose afterwards to overcome or to deal with the inconsistency problem.

\section{Frege's path toward the paradox}

As pointed out before in this paper, Frege's work aiming at the construction of a foundation for arithmetic resulted in the publication of three books: BS, GA and two volumes of GG.

The first book, Begriffsschrift ${ }^{7}$ or Ideography, a formula language, modeled upon that of arithmetic, for pure thought is the initial step taken by Frege towards the foundations of arithmetic. Frege called ideography the ideal language written with special

\footnotetext{
${ }^{7}$ The term Begriffsschrift is composed by the term Begriff, that means 'concept', and Schrift, that means 'graph' or 'writing'. In arithmetic and logic language, the latter is understood as 'notation'. Thereby, begriffsschrift can be translated as 'ideography or conceptual notation' (ALCOFORADO, 2009).
}

RBHM, Vol. 19, n 37, p. 95-116, 2019 
symbols, whose main purpose was to reach pure thought, using arithmetic language (VAN HEIJENOORT, 1970). Frege aimed to create a language that could accurately express and reveal scientific truths.

BS shows for the first time the symbolic language that Frege used later to build the axiomatic system for arithmetic, shown in GG, fourteen years after the publication of his first book. BS is also, as will be discussed later, where the paradox shows its very first signs.

In the Die Grundlagen der Arithmetik, or Foundations of Arithmetic: a logicomathematical enquiry into the concept of number, Frege proposed to define or recognize as indefinable the concept of cardinal number, presenting discussions about the nature of the concept of number and truths of arithmetic. The author also makes harsh criticisms towards the pure formalist, empiricist and psychologist conceptions ${ }^{8}$, orientating his arguments to the conclusion of his thesis: a number is a logical object (VILELA, 1996). According to Frege (GA, §87, p.99), "arithmetic becomes simply a development of logic, and every proposition of arithmetic a law of logic, albeit a derivative one". So, for Frege, to build a foundation for arithmetic using logic was to show that arithmetic concepts can be reduced to logic concepts, and that arithmetic propositions can be reduced to logic propositions (ASSIS NETO, 2008). According to Assis Neto (2008, p.124, our translation), it means "to eliminate any diference between logic and arithmetic: arithmetic is logic and logic is arithmetic".

In the first and second volumes of GG (1893, 1903), Frege presents the construction of an axiomatic system for arithmetic, accurately drawing upon the ideography used, which is now more mature. GG and GGII represent the work of a lifetime dedicated to preparation and intellectual maturation to attain the ideal of the foundation of arithmetic through logic. The first volume contains law V, from which the paradox can be derived.

Identifying the exact law that generates the paradox is straightforward, it is mentioned in several literature works (FRAENKEL et. al., 1984; SLUGA 1999; DUMMET 1991; GRATTAN-GUINNESS 1978; GRIFFIN 2004; ALCOFORADO 2009; WEHMEIER 2004). However, understanding the reason why that specific law generates Russell's paradox is not usually thoroughly discussed (FURTH 1964), and here it is of paramount importance to show that Russell's letters did not reveal the paradox where it really was. Some of the definitions and explanations necessary for understanding it were found in Frege's publications, more specifically in BS and GA. Therefore, for a proper analysis of the origins of the paradox and to clarify the role played by Frege in the discussions to solve it, it is important to discuss all the definitions and theorems presented in his work that are relevant to the reconstruction of the paradox, so that it can be identified in its original form. This will be done next.

One of the most meaningful changes in logic introduced by Frege must be presented first: the rejection of "subject and predicate" in the analysis of a proposition, as done by Aristoteles, and the introduction of "function and argument".

Although Frege's logic maintains the principles and rules of Aristotelian logic, which had suffered almost no changes until Frege's period, his logic went beyond

${ }^{8}$ See Vilela (1996). 
Aristotelian's in two aspects: modifying the syllogistics principles of Aristoteles, since the characteristics of arithmetical inferences could not be analyzed in a satisfactory way using syllogisms; and in the conclusion that the conceptual content of one statement is presented, in general, in an imperfect way when we utilize natural language (SLUGA, 1999).

According to Frege, Aristotelian logic is limited to expressing propositions of multiple generality, which are frequently usedl in mathematical theories. Moreover, Frege explained that in natural language, the subject usually gets a featured position, i.e., the subject is commonly the element used to catch the attention of the listener. Because of this, for Frege, the distinction between subject and predicate often uses subjective attitudes and is based on the expectations of the speaker and the listener, which are not objective and logical characteristics. Frege's goal was to prevent any subjectivity in his theories; only logical consequences should be considered. In this way, the division subject/predicate does not make sense in his new logical language.

These facts led Frege to create a more appropriate tool to achieve his goals: a language sufficient to address the conceptual content and express truths of arithmetic, and that has elements borrowed from mathematics itself. All Frege's logic was built upon these ideas and the use of function and argument.

The modification introduced by Frege (using function and argument instead of subject and predicate) can be understood from the following example (in Aristotelian form) given by Frege in BS:

\section{"Hydrogen is lighter than carbon dioxide"}

It is possible to replace the sign "hydrogen" for the sign "oxygen" or "nitrogen", however, the expression will change as well, i.e., one of these signs will take the place of "hydrogen" in the relation. According to Frege, if we could alter an expression this way, then we should establish which terms are stable, that is, which of these represent the totality of the relation, and which ones are replaceable. The stable component is called (by Frege) "function", while the replaceable one is called "argument". The distinction between function and argument is not related to the conceptual content.

In the example given, Frege points out two possibilities to determine what the function is and what the argument in an expression is:

1. Function: "lighter than carbon dioxide"; argument: "hydrogen".

2. Function: "heavier than hydrogen; argument: "carbon dioxide".

Another important example given by Frege is created from the following expressions: "Carbon dioxide is heavier than hydrogen" and "Carbon dioxide is heavier than oxygen". We could consider two equal functions that have different arguments, namely, "hydrogen" and "oxygen"; or we could consider them as two different functions with the same argument, in which the argument would be "carbon dioxide".

In BS, Frege represents a function of one argument by the sign $\Phi(A)$, in which $\Phi()$ represents an undetermined function of argument $A$. According to Frege, this very function, $\Phi(A)$, could be seen as a function of argument $\Phi$, since the function could also be replaced by others, for instance, represented by the signs $\Psi$ and $X$. 


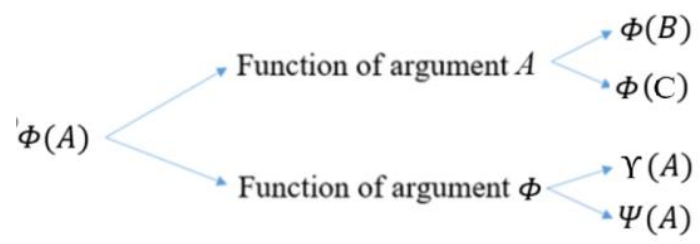

Frege points out that although he uses the concept of function in the analysis as a guide to the development of his theories, this concept is more flexible in the ideography than in the mathematical analysis itself.

According to van Heijenoort (1970, p.3), when Frege establishes that $\Phi(A)$ could be seen as a function of argument $A$ or a function of argument $\Phi$, he in some way anticipates Russell's paradox that will be derived only in GG, because "this is precisely the point that Russell will seize upon to make it bear the brunt of his paradox", as we shall see later.

The way Frege represented and treated propositions in BS was developed into modern mathematical logic (SLUGA, 1999). According to Sluga (1999), this book is possibly the most important work that has ever been written in logic ${ }^{9}$. Frege is considered the creator of mathematical logic.

After publishing BS, the notion of function returns to GA and GG. In GA, this notion appears almost unchanged. What is discussed further in this book and in the paper 'Function and Concept' (1891) is that function and argument are clearly different and complement each other. That is, in the expression $f(x), f()$ represents the function and the function is unsaturated. In other words, it needs a complement, while $x$ is the argument, complete on itself and, therefore, saturated. The argument is not a part of the function, it only complements the function, because the latter is unsaturated and needs a complement. Considering this, together, function and argument are complete.

A function $f()$ becomes saturated when it is accompanied by an argument, say $x$. In this case, $f(x)$, a saturated function, will have a value called by Frege, as we currently do in mathematics, a function value. The value assigned to a saturated function depends on the argument that it receives and the function itself. For instance, given the function $2 x^{2}+x$ and the argument 1 , the value of the function is 3 . However, if we take the number 2 as an argument, then the same function will have the value 10 . What is the same in both cases is that the function returns a number as its value.

If we take the argument $x=1$ or $x=-1$ for the function $x^{2}=1$, the function will not return a number, but "true" as its value. Otherwise, if we take the same function and as its arguments, any other value but $x=1$ or $x=-1$, the left side of the equation will not be equal to the right side and, therefore, it will return "false" as its value. Frege states that in cases such as this, when a function returns as its value "true" or "false", we say that

9 Although nowadays Frege's Begriffsschrift is considered a milestone in mathematical logic, it was not prestigious among mathematicians and philosophers of his time. Begriffsschrift received only six reviews (VILKKO, 1997), most of them criticizing his logical system. 
it returns a truth value. A function may have as a value, numbers, objects in general and/or truth values. When a function has as its value only truth values Frege calls it a concept.

The pairs $(x, f(x))$ represent the course of values of a function. The notion of course of values, fundamental to the construction of the concept of number in GA by Frege, does not appear in BS and is intimately related with the paradox generated in GG.

Another important notion in Frege's theory that is presented in GA, is the notion of an extension of a concept. The extension of a concept corresponds to the course of values, $(x, f(x))$, denoted by Frege as $\grave{\epsilon}(f(\epsilon))$, in which $f()$ is a concept and $f(x)$ is the truth value for the argument $x$. The extension of a concept consists of ordered pairs with one element of the domain, the argument, and one truth value returned by the function when it is filled with the argument in question.

In GA, Frege does not present an accurate definition for the extension of a concept and does not discuss it in-depth. The author takes it as something well known and uses it unrestrictedly. The term extension has already been used in logic before Frege. According to Kneale and Kneale (1978, p. 318), in the book Port Royal Logic ${ }^{10}$ the authors presented the distinction between the "extension" and the "comprehension" of a general term. The latter was related to the set of attributes that a term has, and the former is the set of things that this term is applicable to. Frege discusses this notion later in GGII $(1903, \S 147$, p.278) comparing it to the terms set, class and manifold, commonly used by mathematicians:

"Logicians have long since spoken of the extension of a concept, and mathematicians have used the terms set, class, manifold; what lies behind this is a similar transformation; for we may well suppose that what mathematicians call a set (etc.) is nothing other than an extension of a concept, even if they have not always been clearly aware of this". (FREGE apud BEANEY 2005, p. 228).

It is from the notion of function that Frege defines what for him is an object. Frege's idea differed from the one commonly used to characterize an object. That is, in Frege's point of view, an object is not only what we are able to perceive through the senses, but it is everything that is not an unsaturated function. Specifically, an object is everything that does not have an empty place, i.e., something that is saturated. The objects lack classification because they are, by his logical point of view, all of the same type. Frege presents as examples of logical objects, the arguments, and consequently, numbers and saturated functions. The notion of argument of a function is now extended to any object, including saturated functions.

The identity between concepts is understood by Frege as being determined by the objects of extension, i.e., the relation of identity is a relation between objects (FREGE, GA, 1884). Frege exemplifies this fact using the concept "right angle" and the concept "angle that is equal to its adjacent". Both concepts have the same extension, but not the same content. The extension of a concept is, therefore, totally determined by the concept.

${ }^{10}$ La Logique ou l'Art de penser (or Port Royal Logic as it was mostly known) was published in 1662 by Antoine Arnauld and Pierre Nicole (both from the Port Royal movement). See Kneale and Kneale (1978, p. 298-320).

RBHM, Vol. 19, no 37, p. 95-116, 2019 
When an object may become an argument for a concept, Frege says that this object "falls under" the concept. In other words, given the concept "capital of Brazil", "Brasília" falls under this concept. The notion of "to fall under" is related to the membership relation. That is, using our last example, "Brasília" belongs to the set of elements that satisfies the property "capital of Brazil". According to Frege, a concept must be well defined to decide whether or not an object falls under it.

From the notions discussed here, Frege has established the concept of number (GA, 1884): the number zero would be the object that falls under the concept "different from itself"; the number one would be the object that falls under the concept "equal to zero"; the number two would be the object that falls under the concept "equal to zero or equal to one", and so on.

In GG, Frege presented the logical system published for the first time in BS. However, in GG, his ideography is more mature and consolidated. He also uses the same ideas presented in GA, such as course of values, the logical construction of the concept of number and the reductivity of the arithmetic to logic. So, he constructed his basic laws step-by-step, from the most fundamental definitions, such as function, argument, object, to the construction of propositions using his language, the presentation of inference rules and finally the six laws for arithmetic.

In GG, Frege (1893, §18, p.69; §20, p.72) presented his six laws for arithmetic among which there is law V:

$$
(\grave{\varepsilon} f(\varepsilon)=\grave{\alpha} g(\alpha)) \leftrightarrow \forall x(f(x) \leftrightarrow g(x))
$$

This law establishes that two functions have the same course of values, or two concepts have the same extension, $(\grave{\varepsilon} f(\varepsilon)=\grave{\alpha} g(\alpha))$, if, and only if, both have the same value for the same argument $\forall x(f(x) \leftrightarrow g(x))$, setting an identity relation. Therefore, from this statement, Frege understands that "sets" (or classes) are associated to a property. In other words, for any property there is a set of objects that has this property. This would happen even with a contradictory property, which leads to the empty set ${ }^{11}$ (ALCOFORADO, 2009). Likewise, for any set, there is a property of membership associated with it. Thus, basic law V could be understood in the following way: for any property, properly specified, there is a correspondent set. Law V is exactly the one which allows the formulation of the paradox inside Frege's theory. According to Hersh (1997, p.148), "Russell's paradox is catastrophic because it shows a legitimate property that is self-contradictory - a property to which no set can correspond".

It is important for our purposes to point out that neither Frege nor Russell were the first ones to question the accuracy of law V, or, more precisely, the utilization of extension of concepts in the theory. In the introduction of GG Frege says: "a dispute can arise, so far as I can see, only with regard to my basic law concerning courses of values (V)" (GG, 1893, introduction, p. 3). Although he pointed out a potential complication with law V, Frege did not suspect that this would lead to a paradox that would affect his whole theory, since he introduced it anyway, arguing that he believed that this law would be "a law of pure logic" (GG, 1893 introduction, p.4). Frege's mistrust about law V could have been originated from Cantor's opinion. According to Milne (2010), in Cantor's review of GA,

${ }^{11}$ As the property "different from itself" used by Frege in the Foundations to construct the number zero. 
written in 1885, he alerted Frege about taking extension of concepts as the base of his foundation, he acknowledged back then that the existence of the set of all sets could be not possible. About this fact, "opinions divide whether Cantor's warning was obscurely put or Frege simply negligent in, apparently failing to understand it” (MILNE, 2010, p. 498).

After presenting Frege's laws, the notions of function (concept) and argument (object), course of values (extension of a concept) and falling under a given concept (membership), Russell's discovery and discussions between him and Frege can be analyzed. Furthermore, we can now analyze the discussions about the paradox presented in GGII, as will be done in the next section.

\section{Frege's relation with the paradox: from the identification to the attempts of a solution}

This section presents the identification of the paradox by Russell and Frege. We shall discuss in which part of Frege's GG it can be generated, the original formulation of the paradox and also the attempts to solve this problem. It will be shown that, although Russell is the one who sent the letter about a possible inconsistency in Frege's theory, it was Frege, most likely influenced by Cantor's warning, who pointed out the exact law that allowed the derivation of the paradox inside his system.

On June 16th, 1902, Russell sent the famous letter to Frege in which he demonstrated his admiration for his work and presented the paradox:

"I have encountered a difficulty only on one point. You assert (p.17) that a function could also constitute the indefinite element. This is what I used to believe, but this view now seems to me dubious because of the following contradiction: Let $w$ be the predicate of being a predicate which cannot be predicated of itself. Can $w$ be predicated of itself? From either answer follows its contradictory. We must therefore conclude that $w$ is not a predicate. Likewise, there is no class (as a whole) of those classes which, as wholes, are not members of themselves. From this I conclude that under certain circumstances a definable set does not form a whole”. (RUSSELL, 1902, p.130).

The statement pointed out by Russell, presented in BS, is the following: "Since the sign $\Phi$ occurs in the expression $\Phi(A)$ and since we can imagine that it is replaced by other signs, $\Psi$ or $X$, which would then express other functions of argument $A$, we can also regard $\Phi(A)$ as a function of the argument $\Phi$ "(BS, $\S 9$, p.24, italics in the original). According to Russell, this statement would allow for working with a type of function with the argument 'function of the function', which would create the paradox. The scheme below shows the different possibilities for this type of function: 


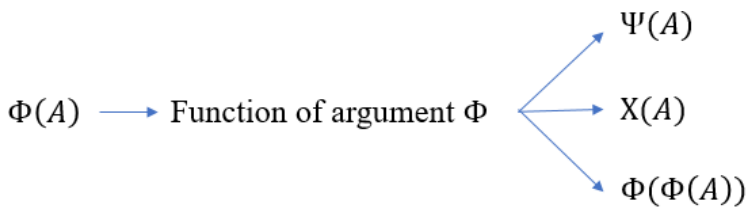

Thus, as expressed by Russell in the letter, it is possible, from this statement, to introduce the following predicate: Let $w$ be the predicate of being a predicate which cannot be predicated of itself. Can this predicate, $w$, predicate itself? In an affirmative case, if $w$ predicates itself, then it must have the property that defines it, say, the property of "not predicating itself", which implies that it cannot predicate itself. On the other hand, if $w$ does not predicate itself, then it must predicate itself, since it has the property that defines it. Therefore, $w$ can predicate itself if, and only if, it cannot predicate itself; which leads to the contradiction.

The version of the paradox that uses predicates did not impress Frege, because it could be solved inside BS, where functions are stratified into levels (WEHMEIER, 2004). Besides, Frege did not use the predicative notion in his theory. In this sense, the predicative version of the paradox could not be derived in GG, because "function could never be meaningful arguments of themselves; predicates could never be meaningful predicates of themselves" (SLUGA, 1999, p.164). However, as could be verified in the letter, Russell also created the version of the paradox using the notion of class, which Frege recognized as something that could be recreated inside his theories, affecting its fundaments, as it will be discussed later in this paper.

The class version would arise when we admit, without distinction, two types of classes: those that belong to themselves and those that do not belong to themselves. Russell considered the class $C$ that contains all the classes that do not belong to themselves. Does this class $C$ belong to itself? For this question, two possible answers follow:

1. If it belongs to itself, it must have the property that defines the class. Then, if $C$ belongs to itself, $C$ is a class that does not belong to itself.

2. On the other hand, if $\mathrm{C}$ does not belong to itself, it has the property that defines it and, therefore, $\mathrm{C}$ belongs to itself.

From the two answers, both imply a contradiction. In other words, class $C$ belongs to itself if, and only if, it does not belong to itself ${ }^{12}$.

Frege (1902, p.132) replied to Russell's letter on July $22^{\text {nd }}, 1902$ using a sentimental and unstable tone about the contradiction: "Your discovery of the contradiction has surprised me beyond words and, I should almost like to say, left me thunderstruck, because it has rocked the ground on which I meant to build arithmetic".

\footnotetext{
${ }^{12}$ Using Frege's terms, the paradox can be rewritten as follows: "If every concept is defined for all objects, then every concept can be thought of as dividing all objects into those that do, and those that do not, fall under it. If extensions of concepts are objects, them extensions themselves can be divided into those that fall under the concept whose extension they are (e.g., the extension of the concept is an extension) and those that do not (e.g., the extension of the concept is a horse). But now consider the concept is the extension of a concept under which it does not fall. Does the extension of this concept fall under the concept or not? If it does, then it does not, and if it does not, then it does" (BEANEY, 2005, p. 229).
} 
In this letter, Frege indicated to Russell that, in fact, the problem could be found in his law $\mathrm{V}$, presented for the first time in $\mathrm{GG}$, and that the logical developments of the paradox would affect not just his own work, but the whole foundation project for arithmetic:

"It seems accordingly that the transformation of the generality of an identity into an identity of range of values ${ }^{13}$ (sect. 9 of my Basic Laws) is not always permissible, that my law V (sect. 20, p.36) is false, and that my explanations in sect. 31 do not suffice to secure a meaning for my combinations of signs in all cases. I must give some further thought to the matter. It is all the more serious as the collapse of my law V seems to undermine not only the foundations of my arithmetic but the only possible foundations of arithmetic as such. And yet, I should think, it must be possible to set up the conditions for the transformation of the generality of an identity into an identity of ranges of values so as to retain the essentials of my proofs". (FREGE, 1902, p.132)

In section 31 of GG, as pointed out by Frege in the quote above, he discusses the idea that in his ideography, his signs composed of simple names, such as truth values, firstlevel, second-level and third-level functions always have a denotation, i.e., a reference. Thus, any course of values, or any extension of a concept, " $\dot{E}(\phi(\epsilon))$ ", would have a reference, i.e., it is a logical object. Furthermore, Frege realized that the contradiction identified by Russell made law $\mathrm{V}$ invalid. This occurred since in the derivation of the paradox, law V features prominently (WEHMEIER, 2004).

The ideography derivation of Russell's paradox from law V is not straightforward, even for authors involved in this discussion (FURTH, 1964). The derivation of the paradox is immediate if we consider the analisys of law V's corollary (presented by Frege in BLAI, $\S \S 54$, p.123) that in current language can be written as follows:

$$
f(a) \leftrightarrow a \in \dot{\epsilon} f(\epsilon) \text {. }
$$

This corollary says that an object $a$ falls under a concept $f$ if, and only if, this object is a member of the extension of this concept. Let's replace " $f(\xi)$ " by " $\neg(\xi \in \xi)$ ", that is $f(\xi)$ is the concept "something that does not belong to itself". Then, we replace, " $a$ " by " $\grave{x}(\neg(x \in x))$ ", that is, $a$ is the class of the classes that do not belong to themselves. From these replacements, we have:

$$
\neg((\grave{x}(\neg(x \in x)) \in(\grave{x}(\neg(x \in x)))) \leftrightarrow \grave{x}(\neg(x \in x)) \in \grave{x}(\neg(x \in x)) .
$$

In other words, the class of the classes that do not belong to themselves, does not belong to itself if, and only if, it belongs to itself; which again is contradictory.

Russell presented three forms of the paradox: the class, the predicate versions in this letter and, later the propositional version. All of them seemed serious to him. However, "for Frege, the significance of Russell's discovery was quite different. The problem seemed to him to be due to the way in which he had introduced logical objects" (SLUGA, 1999, p.164).

\footnotetext{
${ }^{13}$ Range of value and course of value are the same concept, it depends on the translation.
} 
The paradox reaches the notion of course of values of a function, or extension of a concept, understood as something complete in itself and, because of it, as something that could be taken as the argument of a function. The whole of Frege's system was created according to this notion. The concept of number in Frege, as we have seen, has a definition involving the notions of extension of a concept (classes), falling under a concept (membership) and one to one correspondence. Therefore, when the notions of course of values and extension of a concept were shaken, the concept of number and all Frege's system for the arithmetic have been shaken together. According to Frege, one logical foundation for arithmetic could not be created without resorting these notions (FREGE, 1903).

Thus, Frege's reaction when he noticed that Russell's discovery would affect not just the system built by him but any logic foundation for arithmetic, shows the dimension of the problem found by Russell. When Russell first heard about Frege's work, he hoped it might "cointain some solution to the paradox, showing the contradiction to be merely apparent" (BURGESS, p. 32). Griffin (2004) and Wehmeier (2004) claim that, when analyzing Frege's work, Russell had noticed a problem, but he could not measure the real consequences. Frege's response for the letter made Russell realize that the paradox would be more difficult to solve than he could have imagined (GRIFFIN, 2004).

At the end of the letter, Frege (1902, p.132) says: "Your discovery is at any rate a very remarkable one, and it may perhaps lead to a great advance in logic, undesirable as it may seem at first sight". Therefore, he believed that the identification of the paradox would promote great advances in logic. Thus, besides creating a new logic, which culminated in the modern mathematical logic, Frege also managed to identify the origin and the consequences of the paradox in his theories. We can also imply a possible and most likely influence of Cantor in this question. He had already expressed his opinion against taking courses of values as a base for the theory. Although Frege might have not understood the real problem at that time, this warning might have disturbed his thoughts since, as discussed before, he claimed in the introduction of GG that a dispute could arise regarding his law V. We believe that Cantor's review might have been the origin of Frege's mistrust or insecurity about law $\mathrm{V}$ since he presented that affirmation without giving any plausible reason for this.

In the second letter from Russell to Frege, he expressed in a simplified way how he had created the paradox. Although Russell recognized that the paradox could be derived in Frege's system, it had been built before from Georg Cantor's ${ }^{14}$ studies, specifically in the analysis of the diagonal argument used by Cantor in the proof that there is no greatest cardinal number (GRATTAN-GUINNESS, 1978). Therefore, the paradox derived from Frege's theory is the same that had been derived from Cantor's theory. It is also relevant to point out that Cantor independently identified the paradox inside his own theories but did not publish it (GRATTAN-GUINNESS, 1978).

\footnotetext{
14 According to Haddock (2006), Rang and Thomas (1981), Ernst Zermelo would also have identified Russell's paradox independently. This may have happened one or two years before Russell's discovery (RANG; THOMAS, 1981), while Zermelo studied Husserl's review of Schröder works.
} 
We can see here how interconnected Cantor's, Russell's and Frege's studies were. Although they worked independently, they got to similar conclusions, which is plausible since they all were studying foundation related topics. Their work somehow complemented each other, so that the recognition and account of each other work was fundamental to the identification and the understanding of the paradox's consequences.

In the other correspondences between the mathematicians, from June $29^{\text {th }}, 1902$ until December $12^{\text {th }}, 1904^{15}$, Russell and Frege discussed possibilities to solve the paradox. Most of the attempts were proposed by Russell and rejected by Frege. All the discussions of these attempts are beyond the scope of this paper but can be found in Long and White's (1980) work. In this paper, we shall briefly discuss two of these proposals, which were presented by Frege in the epilogue of GGII.

The first attempt of eliminating the paradox made by Russell covers the definition of classes. For Russell, classes cannot be treated as other objects: "I believe that classes cannot always be admitted as proper names. A class consisting of more than one object is in the first place not one object but many" (RUSSELL, 1902, p.138). Regarding assuming classes as a different type of object, say, improper objects, Frege argued:

"I have considered various possible ways of resolving the contradiction, and among this also the one you indicated, namely that we are to conceive of ranges of values and also of classes as a special kind of object whose names cannot appear in all argument places of the first kind". (FREGE, 1902, p.145).

One of the difficulties raised by this proposal, classes and courses of values considered as improper objects, would be creating rules to set up the types of arguments that a function would receive. That is, not all functions would accept improper objects as arguments. Some of them would accept both improper and proper objects, or even just improper objects. How would we establish which functions would receive which types of objects as arguments? Frege believed that this could not be the way to free the theory from paradoxes. Later, Russell further explored the idea of establishing function types, that is, to restrict the membership of the course of values in order to avoid the paradox. The outcome was the type theory presented by Russell and Alfred North Whitehead (1861-1947) in Principia Mathematica (1910).

Russell's studies on the foundations of mathematics is mostly known through the books Principia Mathematica and Principles of Mathematics (1903). Although the book Principles of Mathematics presents the outset of a type theory, Russell claims that the Principles was already in the press when he started to study Frege's work more deeply. Giuseppe Peano (1858-1932), whom Russell had met in 1900, inspired Russell to read Frege (BEANEY, 2005), (KENNEDY, 2002). After reading Frege's work, Russell decided to include the appendix A in the Principles. Although Russell had had access to Begriffsschrift long before this, he claimed that he could not understand it until he had

\footnotetext{
${ }^{15}$ In this period, the mathematicians exchanged fifteen letters: eleven of them in 1902; three in 1903 and two in 1904.
} 
himself "independently discovered most of what it contained" (BEANEY, 2005, p. 215). Therefore, despite the appendix A, Frege's influence in the rest of the contents of the Principles could have only been possible through Peano's work ${ }^{16}$.

The second proposal for eliminating the paradox was presented by Frege to Russell on October 20th, 1902 in one of the letters and afterwards, in the appendix of GGII, in which Frege discussed the paradox. In this appendix, Frege (1903) derived the paradox using his ideography.

Law $\mathrm{V}$ consists of two implications, namely law $\mathrm{Va}$ and $\mathrm{Vb}$ which are, respectively:

$$
\begin{gathered}
\forall x(f(x) \leftrightarrow g(x)) \rightarrow(\grave{\varepsilon} f(\varepsilon)=\grave{\alpha} g(\alpha)) \\
\text { and } \\
(\grave{\varepsilon} f(\varepsilon)=\grave{\alpha} g(\alpha)) \rightarrow \forall x(f(x) \leftrightarrow g(x))
\end{gathered}
$$

The derivation shows that the paradox arises when only law $\mathrm{Vb}$ is considered and, as a consequence, it should be false. According to Frege, along with law Vb, law V should be false as well, however, law Va remained intact. It is possible to go from the generality of an identity to an identity of a course of values. The problem lies in the inverse problem, that is, when we try to go from an identity of a course of values to the generality of an identity.

Therefore, the proposal presented by Frege considers the substitution of law V and law $\mathrm{Vb}$ for other more attenuated versions, which exclude the possibility of an extension of a concept falling under its own concept. The solution found by Frege was to set up a "weak" version of these laws that would be useful to maintain his idea of foundation of arithmetic using logic. The law V', replacement of law V, is expressed by Frege in the following way:

$$
(\grave{\epsilon} f(\epsilon)=\grave{\alpha} g(\alpha)) \leftrightarrow(\forall a((a \neq \grave{\epsilon} f(\epsilon) \wedge a \neq \grave{\alpha} g(\alpha)) \rightarrow(f(a) \leftrightarrow g(a))))
$$

The law V' asserts that the courses of values (or extension of a concept) of the functions (or concepts) $f(\xi)$ and $g(\zeta)$ are equal if, and only if, for all arguments " $x$ " different of $\grave{\epsilon} f(\epsilon)$ and $\grave{\alpha} g(\alpha), f(x) \leftrightarrow g(x)$. This law implies law Va. However, Vb becomes V'b and V'c, expressed below:

$$
\begin{gathered}
((\grave{\epsilon} f(\epsilon)=\grave{\alpha} g(\alpha)) \rightarrow(\neg(a=\grave{\epsilon} f(\epsilon))) \rightarrow(f(a) \leftrightarrow g(a) \\
((\grave{\epsilon} f(\epsilon)=\grave{\alpha} g(\alpha)) \rightarrow(\neg(a=\grave{\alpha} g(\alpha)))) \rightarrow(f(a) \leftrightarrow g(a))
\end{gathered}
$$

Despite the introduction of these changes, it is possible to show that Frege's new laws also generate a contradiction. The polish logician Stanislaw Lesniewski (1927-1934) proved it some years after the laws had been presented by Frege (HADDOCK, 2006). Frege

\footnotetext{
${ }^{16}$ According to Kennedy (2002), Russell could have studied Frege's work through Peano's review of GG (PEANO, 1895) and his paper Formules de Logique Mathématique published in Rivista di Matematica (PEANO, 1900).
} 
had not known about this fact before he passed away, but he neither showed himself satisfied with this alternative of a solution, since he was discouraged about the idea to reduce arithmetic to logic.

In the last letters exchanged between Frege and Russell, the mathematicians discussed some more proposals indicated by Russell, including one that builds arithmetic without the idea of classes, which, in Frege's mind, would also be insufficient. The very last letter sent by Russell to Frege was lost (LONG; WHITE, 1980). In Frege's answer to that letter, he refused an invitation to take part in a mathematics conference and was disheartened about discussions and academic appearences. Slowly, Frege deserted what is nowadays known as the logicist project.

After publishing GGII, Frege did not publish meaningful works about mathematics foundations. In 1918, he started to write a work about philosophical logic, but he passed away before concluding it.

At the end of his life, Frege abandoned the logicist program, claiming that maybe the whole of mathematics was sustained by geometry and not by logic (HERSH, 1997). According to Alcoforado (2009, p.38, our translation), Frege could have had this idea because he was not able to find an alternative that overcame the dificulties which arose from Russell's paradox, appealing "to the synthetic and a priori knowledge".

The dream of a foundation of mathematics through logic was definitely shaken by Gödel's incompleteness theorems in 1931. Gödel devastated the mathematical world with his incompleteness theorems, showing that it is impossible to create a complete and consistent system for arithmetic using classical logic.

However, between the publication of Russell's Principia and the appearance of Gödel's theorems, mathematicians were divided between different paths. Some of them were trying to build a foundaiton to classical mathematics using axiomatic set theory formulations, such as Zermelo and Fraenkel's, while others tried to create systems similar to Russell's type theory. Some ideas diverged completely from those, their groundwork was "philosophical points of view from which these systems, and with them much of classical mathematics were unacceptable" (BURGESS, 2005, p. 50). One example of this type of theory is David Hilbert's finitism, which repudiated the "actual infinite"17.

Therefore, the attempts to solve the foundation problem, not only Russell's paradox, became a tool for the development of type theory, set theory and non-classical logic, for instance. Each of these theories have systems that try to control, from different ways, the uncomfortable situation created by the paradoxes (D'OTTAVIANO, 1990). Type theory and set theory used the traditional classical logical paradigm, while non-classical logics, as their own names suggest, questioned the acceptance of the traditional classical logic principles.

Frege's work played a fundamental role in the discussions about the foundations of arithmetic and about the paradox. His perception about the paradox fertility for mathematics and logic history was surprisingly precise. In the next section, the theoretical developments after the paradox will be presented and how they are related to the discussions Frege had presented in his GGII.

${ }^{17}$ See Burgess (2005).

RBHM, Vol. 19, no 37, p. 95-116, 2019 


\section{Reaffirming the role of Frege: a revolution in logic and philosophy of mathematics}

As we have seen, Frege tried untiringly to construct a foundation for arithmetic using logic. His efforts and dedication to accomplish this goal, concentrated in more than twenty years of work, culminated in three important publications: BS, GA and GG in two volumes. These works are not just what today is called mathematical logic, but also set a research agenda in logic, philosophy and mathematics fields.

Frege's academic life has been defined by his search to clarify all arithmetic notions, definitions, propositions and inference laws, which was a tiresome search for the truth and certainty. He always believed that it would be possible to set mathematics free from ambiguities and contradictions. After discovering the paradox, Frege could not find a satisfactory way of either abandoning or adapting the notion of course of value (or extension of a concept), in order to avoid the paradox. Nevertheless, the proposals presented by him to prevent the generation of the paradox foresaw the solutions given by other authors some years later, which was well accepted by the academy. These attempts led to ways of avoiding the paradoxes but not to a perfect language (COURY, 2015), as will be discussed later.

The first proposal to circumvent Frege's paradox focused on eliminating impredicativity, which was later shown by Russell and Whitehead in type theory. This idea was the first solution discussed by Frege and it proposed to take the extension of concepts as a different kind of object, rather than proper objects. The second proposal, replacing the law $\mathrm{V}$, may be seen as a root of the separation axiom, which is a restriction proposed later by Zermelo in his formulation of axiomatic set theory.

The correspondence between Frege and Russell shows, for instance, the road that Russell travelled on his own foundation project, shown in the Principles of Mathematics and in Principia Mathematica. Specifically, about the Principles, although it had already been sent to the press when Russell started to study Frege's work more intently, he wrote an appendix discussing Frege's work to add to the Principles, showing that Frege's ideas had a strong influence in the development of his own theories. Appendix A is dedicated to Frege's theory and presents some of the discussions contained in the letters, where Russell presents and clarifies some parts of the theory, as the concept of course of values, truth values, object and concept, sense and reference (RUSSELL, 1902). Appendix B, in which Russell presents a simple type theory, is undoubtedly a consequence of these discussions, that is, an attempt to avoid the paradox ${ }^{18}$.

Athough the Principles present the discussions and/or developments of Frege's ideas in boths appendixes, Russell had claimed several times that the rest of the ideas presented in the book were the result of Peano's and Cantor's influence (HYLTON, 2010). Chapter 10, for example, discusses the paradox from Cantor's theory point of view, not Frege's one. Nevertheless, Principia Mathematica shows and claims to be highly

18 Russell begins appendix $B$ in the following way: "the doctrine of type is here put forward tentatively, as affording a possible solution of the contradiction; but it requires, in all probability, to be transformed into some subtler shape before it can answer all the difficulties" (Principles of Mathematics, 1903, appendix B, p. 534). 
influenced by Frege. Whitehead wrote in his preface "in all questions of logical analysis, our chief debt is to Frege" (HYLTON, 2010, p. 513).

Importantly, Frege's work went beyond the famous paradox. He revolutionized logic and gave dimension to Russell's paradox, pointing out its consequences not just for the axiomatic system built by him, but also for other systems that were constructed using traditional classical logic and set theory. Furthermore, he attested that any foundation of arithmetic would be affected if it were based on these principles. Some years after that, in 1931, Gödel proved the failure of the ideal of the arithmetic foundation using classical logic systems. Therefore, Frege was also accurate when he claimed that any arithmetic foundation, using logic, would be affected, not just the one built by him. Gödel's theorems show that there are mathematical truths that cannot be proved, i.e., an axiomatic system that is complete and consistent cannot be constructed while covering the whole of arithmetic.

Concerning philosophical developments, the ideas of the famous philosopher Wittgeinstein (1889-1951) also have their roots in Frege's work. First, in the Tratactus Logico-Philosophicus (1922), Wittgeinstein, influenced by Frege's work and under the supervision of Russell at Cambridge University, created his own study of logic. According to Beaney (2005, p.233), maybe the "single biggest effect that Frege had on Russell after 1903 was in recommending to Wittgenstein that he study with Russell". Wittgeinstein sought a relation between language and the world in his Tratactus. He followed the context principle from Frege and in his attempts to fit the language into a logical format reached the "limits of the language" (LECLERC, s/d, p. 45) ${ }^{19}$, that is, he faced the impossibility of an ideal language. The philosophical movement known as linguistic turn, frequently associated to Wittgenstein, is characterized by the anti-idealism and anti-representational features of the language.

Currently, Frege's works have been summarized by many authors in logic and philosophy (DA SILVA, 2007). They acknowledge that Frege's inconsistent system may be the key for the development of amended and paradox free versions of the system, what has already been done. According to Burgess (2005, p.1), "substancial portions of classical mathematics have been developed within such systems, and a number of workers have claimed philosophical benefits for such an approach to the foundations of mathematics".

In sumary, reconstructing the paradox in its mathematical specificities, enabled us to understand the role played by Frege in its identification and how his works traced the path for the development of new theories. Overall, the studies discussed here show how Frege's studies had impacted and will continue to impact the development of mathematics, logic and philosophy.

\section{References}

ALCOFORADO, P. 2009 (2 ${ }^{\mathrm{a}}$ Ed.). Lógica e Filosofia da Linguagem. São Paulo, SP: Editora da Universidade de São Paulo.

\footnotetext{
${ }^{19}$ There is no disagreement that Wittgensteins' studies about the foundations have an intimate relation, although contrary to Frege's theory.
}

RBHM, Vol. 19, no 37, p. 95-116, 2019 
ASSIS NETO, F.R. 2008. Prefácio ao Begriffschrift de Gottlob Frege (1848-1925): tradução e introdução ao texto. In: Revista Brasileira de História da Matemática, vol. 8, n.16. 123-141.

BACHA, M.L.; SAITO, F. 2014. Peirce e Cantor: um estudo preliminar sobre continuidade e infinitesimais. In: Revista Brasileira de História da Matemática. vol. 14, n.28. 1-23.

BEANEY, M. 2005. Frege, Russell and logicism. In: Gottlob Frege: Critical assessments of leading philosophers (pp. 213-233). New York: Routledge.

BURGESS, J. P. 2005. Fixing Frege. New Jersey: Princeton University Press.

COURY, A. G. F. 2015. Frege e as leis da aritmética: do ideal de fundamentação ao paradoxo. Dissertação (Mestrado). Universidade Federal de São Carlos.

DA SILVA, J.J. 2003. O Segundo Problema de Hilbert. In: Revista Brasileira de História da Matemática. vol. 3, n.5. 29-37.

DA SILVA, J.J. 2007. Filosofias da Matemática. São Paulo: Editora Unesp.

DAVIS, P.J. \& HERSH, R. 1981. The Mathematical Experience. Boston: Mariner Books.

D’OTTAVIANO, I. M. L. 1990. Paradoxos auto-referenciais e as lógicas não clássicas heterodoxas. In: Ciência e Cultura. vol. 42, n. 2. 164-123.

DUMMET, M. 1991. Frege: Philosophy of Mathematics. London: Duckworth.

FRAENKEL, A. A., BAR-HILLEL, Y., LEVY, A. 1984. Foundations of Set Theory. Holanda: Elsevier Science Publishing Company.

FREGE, G. 1970 Begriffsschrift: a formula language, modeled upon that of arithmetic, for pure thought. In: J. van Heijenoort (Ed. and Trans.) Frege and Gödel: two fundamental texts in mathematical logic. Cambridge, Massachusetts: Harvard University Press.

FREGE, G. 1980. Frege to Russell. In: P. G. Gabriel, H. Hermes, F. Kambartel, C. Thiel, A. Veraart (Ed.) P. Long \& R. White (Trans.) Gottlob Frege: philosophical and mathematical correspondence. (pp. 130-170). United Kingdom: Basil Blackwell - Oxford.

FREGE, G. 1964. The Basic Laws of Arithmetic. In: M. Furth (Ed. and Trans.) The Basic Laws of Arithmetic: exposition of the system. Berkeley, Los Angeles: University of California Press.

FREGE, G. 1960. The Foundations of Arithmetic: a logico-mathematical enquiry into the concept of number. J. L. Austin (Trans.). New York: Harper \& Brothers.

FURTH, M. 1964. Introduction. In M. Furth (Ed.) The Basic Laws of Arithmetic: exposition of the system. Berkeley, Los Angeles: University of California Press.

GOLDSTEIN, R. 2008. Incompletude: a prova e o paradoxo de Kurt Gödel. I. Korytowski (Trans.) São Paulo: Companhia das Letras.

GRATTAN-GUINNESS, I. 1978. How Bertrand Russell Discovered his Paradox. In: Historia Mathematica. vol. 5, n.2.127-137.

GRIFFIN, N. 2004. The Prehistory of Russell's Paradox. In: One Hundred Years of Russell's Paradox: mathematics, logic, philosophy (pp.349-371). Berlin: Walter de Gruyter.

GUILLEN, M. 1983. Pontes para o Infinito: o lado humano das matemáticas. J. S. Branco (Trans.). Portugal: Gradiva.

HADDOCK, G. E. R. 2006. A Critical Introdution to the Philosophy of Gottlob Frege. Puerto Rico: Ashgate. 
HEATH, T. L. 1956 (2 $2^{\text {a }}$ Ed.). The Thirteen Books of Euclid's Elements. vol. 1. New York: Dover Publication.

HERSH, R. 1997. What is mathematics, really? New York: Oxford University Press.

HYLTON, P. 2010. Frege and Russell. In: The Cambridge Companion to Frege (pp. 509549). United Kingdom: Cambridge University Press.

KENNEDY, H. 2002. What Russell Learned from Peano. In: Twelve Articles on Giuseppe Peano. San Francisco: Peremptory Publications, 28-34.

KNEALE, W. \& KNEALE, M. 1978. The Development of Logic. Great Britain: Oxford University Press.

LECLERC, A. 2008. Mente e linguagem. In: Ciência e Vida. Filosofia especial. São Paulo: Dibra, ano II, n. 9, 40-53.

LONG, P. \& WHITE, R. 1980. Introduction and comments. In: Gottlob Frege: philosophical and mathematical correspondence. United Kingdom: Basil Blackwell Oxford.

MILNE, P. 2010. Frege's folly: bearerless names and Basic Law V. In: The Cambridge Companion to Frege (pp. 465-508). United Kingdom: Cambridge University Press.

PEANO, G. 1895. Review of G. Frege, Grundgesetze der Arithmetik, begriffsschriftlich abgeleitet, vol. 1. In: Rivista di Matematica. vol.5, 122-128.

PEANO, G. 1900. Formules de Logique Mathématique. In: Rivista di Matematica. vol. 7, $1-40$.

RANG, B. \& THOMAS, W. 1981. Zermelo's Discovery of the "Russell Paradox". In: Historia Mathematica. $\mathbf{n . 8}, 15-22$.

RUSSELL, B. 1980. Russell to Frege. In: P. G. Gabriel, H. Hermes, F. Kambartel, C. Thiel, A. Veraart (Ed.) P. Long \& R. White (Trans.) Gottlob Frege: philosophical and mathematical correspondence. (pp. 130-170). United Kingdom: Basil Blackwell - Oxford. RUSSELL, B. 2010. Principles of Mathematics. London: Routledge.

RUSSELL, B. \& WHITEHEAD, A. N. 1999. Principia Mathematica. United Kingdom: Cambridge University Press.

SLUGA, H. D. 1999. The Arguments of the Philosophers: Gottlob Frege. London: Routledge.

VAN HEIJENOORT, J. 1970. Introduction. In: Frege and Gödel: two fundamental texts in mathematical logic. Cambridge, Massachusetts: Harvard University Press.

VILELA, D. S. 1996. Análise das Críticas de Frege à Cantor: a noção de número e o emprego da abstração nas definições. Dissertação de Mestrado. Universidade Estadual de Campinas. Campinas, SP.

VILKKO, R. 1998. The reception of Frege's Begriffsschrift. In: Historia Mathematica. n. 25, 412-422.

WEHMEIER, K. F. 2004. Russell's Paradox in Consistent Frangments of Frege's Grundgezetze der Arithmetik. In: One Hundred Years of Russell's Paradox: mathematics, logic, philosophy (pp.349-371). Berlin: Walter de Gruyter.

WITTGENSTEIN, L. F. 1922. Tractatus Logico-Philosophicus. London: Kegan Paul, Trench, Trubner \& Co. 


Aline Germano Fonseca Coury
Departamento de Educação - PPGE - UFScar - São
Carlos - Brasil
E-mail: alinee_fonseca@ @otmail.com
Denise Silva Vilela
Departamento de Metodologia de Ensino - DME -
UFScar - São Carlos - Brasil
E-mail: denisevilela@ ufscar.br

